\title{
PROTON IRRADIATION DAMAGE OF AN ANNEALED ALLOY 718 BEAM WINDOW
}

\author{
H. T. Bach ${ }^{1}$, O. Anderoglu ${ }^{1}$, T. A. Saleh ${ }^{1}$, T. J. Romero ${ }^{1}$, C. T. Kelsey ${ }^{1}$, E. R. Olivas ${ }^{1}$, B. H. Sencer ${ }^{2}$, P. O. \\ Dickerson $^{1}$, M. A. Connors ${ }^{1}$, K. D. John ${ }^{1}$, and S. A. Maloy ${ }^{1}$ \\ ${ }^{1}$ Los Alamos National Laboratory, Los Alamos, NM 87545 \\ ${ }^{2}$ Idaho National Laboratory, Idaho Falls, ID 83402
}

\begin{abstract}
Mechanical testing and microstructural analysis was performed on an Alloy 718 window that was in use at the Los Alamos Neutron Science Center (LANSCE) Isotope Production Facility (IPF) for approximately 5 years. It was replaced as part of the IPF preventive maintenance program. The window was transported to the Wing 9 hot cells at the Chemical and Metallurgical Research (CMR) LANL facility, visually inspected and 3-mm diameter samples were trepanned from the window for mechanical testing and microstructural analysis. Shear punch testing and optical metallography was performed at the CMR hot cells. The 1-mm diameter shear punch disks were cut into smaller samples to further reduce radiation exposure dose rate using Focus Ion Beam (FIB) and microstructure changes were analyzed using a Transmission Electron Microscopy (TEM). Irradiation doses were determined to be $\sim 0.2-0.7$ dpa (edge) to $11.3 \mathrm{dpa}$ (peak of beam intensity) using autoradiography and MCNPX calculations. The corresponding irradiation temperatures were calculated to be $\sim 34^{\circ} \mathrm{C}$ to $120^{\circ} \mathrm{C}$ with short excursion to be $\sim 47^{\circ} \mathrm{C}$ to $220^{\circ} \mathrm{C}$ using ANSYS. Mechanical properties and microstructure analysis results with respect to calculated dpa and temperatures show that significant work hardening occurs but useful ductility still remains. The hardening in the lowest dose region $(\sim 0.2-0.7 \mathrm{dpa})$ was the highest and attributed to the formation of $\gamma^{\prime \prime}$ precipitates and irradiation defect clusters/bubbles whereas the hardening in the highest dose region ( $11.3 \mathrm{dpa})$ was lower and attributed mainly to irradiation defect clusters and some thermal annealing.
\end{abstract}

\section{INTRODUCTION}

During the operation at the Los Alamos Neutron Science Center (LANSCE) Isotope Production Facility (IPF) an Alloy 718 beam window (initially in the annealed state) was subjected to stress-induced from a differential pressure across the beam window as well as from a thermal volume heating by energy deposition of $100 \mathrm{MeV}, 250 \mu \mathrm{A}$ proton beam. In addition, under irradiation conditions, significant microstructure alterations are expected due to a high level of atomic displacements induced by energetic proton (primary) and neutron (secondary) irradiation. Defect structures such as dislocation and vacancy loops, vacancy clusters, voids, 
helium and hydrogen bubbles form as a function of operating temperature and proton and neutron fluences that are quantified into total irradiation dose using the displacement-per-atom (dpa) unit. These cumulative factors may result in dramatic changes in macroscopic material properties of the window causing it to become less ductile and more prone to failure in use. The beam window was in operation in the period May 2004 to December 2009 with accumulated proton charge of $0.394 \mathrm{~mA}-\mathrm{y}$. The beam window was replaced in March 2010 as part of the IPF preventive maintenance program. The estimated dose rate without any shielding from all gamma emitting isotopes produced inside the beam window was $100 \mathrm{R} / \mathrm{hr}$ at one foot. The beam window was stored in a shielded cask for several months to "cool down" and transported to the Chemical and Metallurgical Research (CMR) LANL facility in November 2010. The results from this study will be important to provide mechanical and microstructure properties of an irradiated Alloy 718 alloy and an understanding on how these properties of the beam window degrade under extreme irradiation conditions with a high power proton beam and to aid in deciding when to replace the beam window or how to choose a new window material and designs with longer extended lifetimes.

\section{MATERIALS AND METHOD}

\subsection{Beam window design}

The LANSCE IPF extracts the $100 \mathrm{MeV} \mathrm{H}^{+}$beam from the LANSCE accelerator and delivers it to isotope production targets inside a target chamber, which is heavily shielded with concrete and steel structure. The proton beam is transported and delivered to IPF targets via a beam pipe that extends to the target chamber. The window is fabricated from an annealed Alloy 718 bar stock with a diameter of $76.2 \mathrm{~mm}$ and a thickness of $0.5 \mathrm{~mm}$. The Alloy 718 window is e-beam welded to the end of the stainless steel beam transport pipe assembly per ASME Section IX Welding and Brazing. The window serves as a barrier between the accelerator beam components, which is kept under vacuum, and the target chamber, which is kept at $12.2 \mathrm{~m}$ height of cooling water column under atmospheric pressure. Therefore, the integrity of the beam window is critical because if it failed, target cooling water would flood the IPF beam line, excessively damage equipment and severely impact or even halt the isotope production operations.

\subsection{Visual examination}

The CMR hot cell with shielding, crane capacity, remote handling and metallographic equipment provides a unique capability to handle and evaluate the IPF highly activated beam window. The shielded beam window assembly was unloaded with a 10-ton crane, and the window assembly was removed out of the shielded cask with manipulators, and cut from the beam pipe with a portable band saw. The window shows a ring-shaped beam profile, which is slightly off -center (Fig. 1). The thickness and height variations across the window were measured using a micrometer. We found that the window thickness had increased $\sim 8 \%$ at the 
maximum beam intensity location with respect to that at the low beam intensity location and the chemical content of this layer was not analyzed. The window bulged into the vacuum side $\sim 1.5$ $\mathrm{mm}$ at the center with respect to the outermost perimeter.

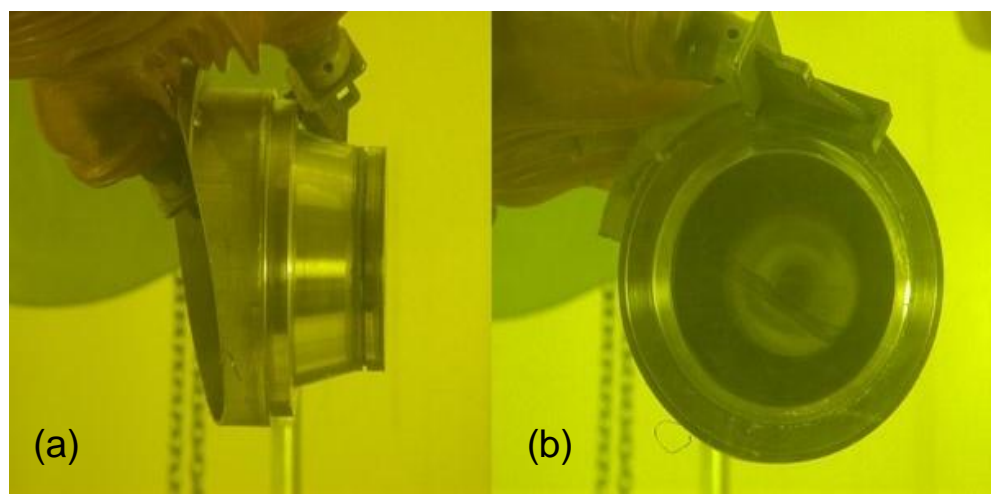

Fig.1: A side view of the end of the pipe containing the actual beam window (a) and the beam window itself with a beam ring-shaped profile (b).

\subsection{Beam profile measurement}

Tungsten wires were placed on the window to mark the window orientation on the autorad image. Gafchromic film HD-810 dosimetry films were exposed to measure the absorbed dose of high energy photons from the activated beam window. The pixels (dose) intensity was analyzed along the marked rectangular selection (Fig. 2a) with ImageJ. The darkest blue region on the Gafchromic film corresponds to the highest beam intensity region. The centers of the beam and the window were not aligned. The center of the beam was shifted $0.96 \mathrm{~mm}$ to the right and $4.39 \mathrm{~mm}$ to the bottom with respect to the center of the window. Vertical and horizontal intensity profiles through the beam center are plotted in Fig. 2c. The most intense region of the profile is closely approximated using MCNPX by rastering a $20.5 \mathrm{~mm}$ FWHM beam in a circle with a radius of $17.0 \mathrm{~mm}$, but the tails are overestimated [1]. For our MCNPX heating and damage calculations we instead used a symmetric average of the measured vertical and horizontal profiles to obtain a radial probability density function. Fig. $2 \mathrm{c}$ is a $3 \mathrm{D}$ beam intensity plot from MCNPX tally.
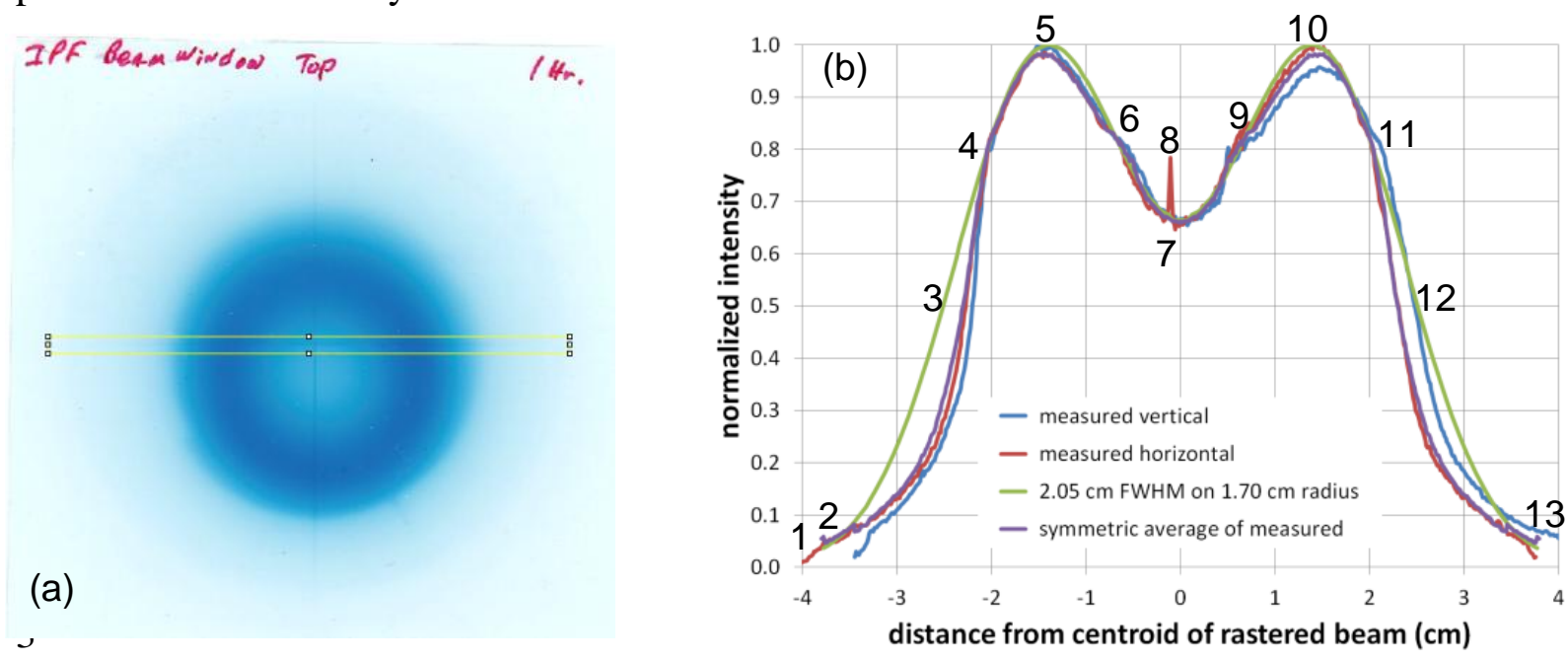


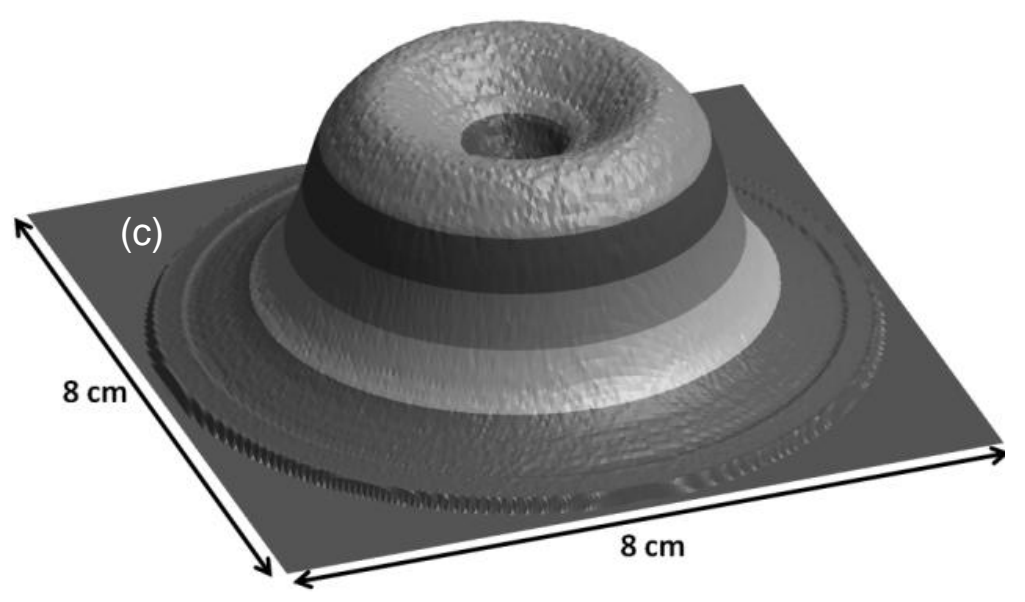

Fig. 2: Autoradiography of beam window with 1 hour exposure (a); measured and calculated beam intensity profiles (b); and a 3D beam profile from MCNPX simulations (c).

\subsection{Sample cutting plan}

The measured beam profile was superimposed on the window to determine the cutting plan as a function of irradiation dose. Twenty-five samples were cut with a 3-mm OD using a milling machine and tungsten carbide trepan tools. The cut-out samples were polished and thinned on both sides to $0.25 \mathrm{~mm}$ thickness. Samples \#3-9 are in the high irradiation area corresponding to the peak of the beam intensity (locations 5 and 10 in Fig. 2b). Samples \#10-14 are outside the beam collimator area (between locations 3-4 and 11-12 in Fig. 2b). Samples \#17-18 and \#19-20 are at the window edge corresponding to a very low or zero dose area (location 2 or 13 in Fig. 2b). In addition, 6 samples were prepared in the same manner from unirradiated Alloy 718 alloy as control samples.

\subsection{MCNPX analysis of beam energy deposition and total fluence}

A model was developed including the beam window along with the proton beam transport vacuum line, target irradiation chamber, isotope production targets, and shielding in three dimensions; material compositions and physical properties; the associated cross-sections libraries; the location and characteristics of the proton beam, and the type of desired results and 
the conditions for running the calculation in MCNP input files as described in Appendix D of the MCNPX user's manual [1].

The radial probability density function developed from the beam profile measurement described above and illustrated in Figs. 2b and 2c was used in MCNPX simulations where heating and displacements per atom (DPA) were tallied in the window by sample radially about the beam center.
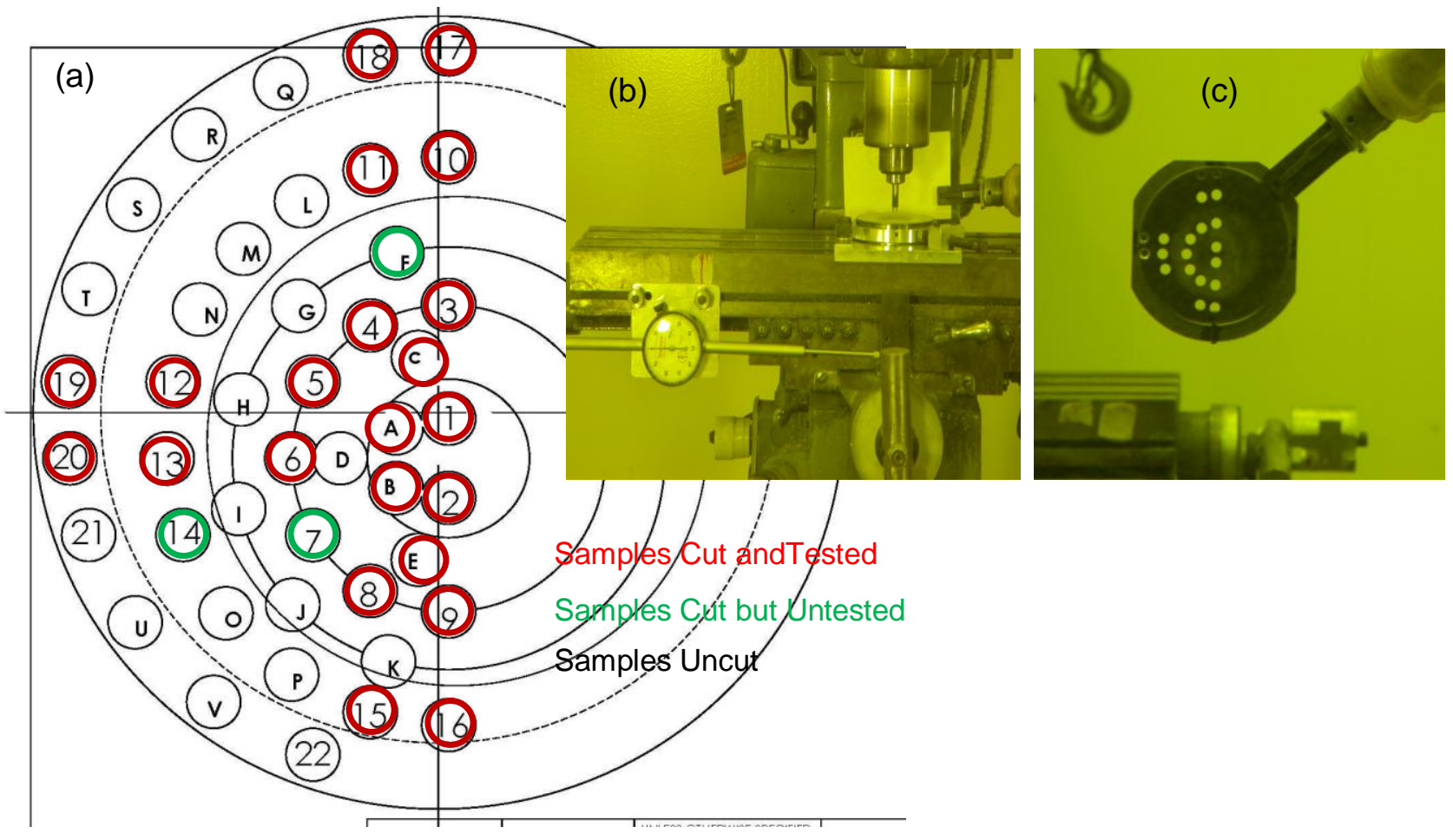

Fig. 3: The beam window cutting plan as a function of irradiation dose (a); a Mill machine and tungsten bit set-up inside the CMR hot cell (b); and a view of a window with cutout samples (c).

The details of the quantification of the fluence in dpa per unit of time can be found elsewhere [2]. Briefly, the rate of number of vacancies/interstitial pairs produced by the reaction per incident particle of energy $E$ per second, $\frac{d N_{d}}{d t}(E)$, is:

$$
\frac{d N_{d}(E)}{d t}=N_{o} \int_{T_{\min }}^{T_{\max }} \phi(E) \sigma(E, T) v(T) d T \quad[\text { Eq. 1] }
$$


where $N$ is the atom number density, $\phi(E)$ is the energy dependent incident particle flux, $T_{\max }$ and $T_{\min }$ are the maximum and minimum energies transferred in a collision of a particle of energy $E$ and a lattice atom, $\sigma(E, T)$ is the cross section for the collision of a particle of energy $E$ that results in a transfer of energy $T$ to the struck atom, $v(T)$ is the number of displacements per primary knock-on atom with displacement energy $T$.

The average number of displacements produced by a collision of an incident proton (or neutron) with energy E can be simplified as:

$$
\frac{N_{d}(E)}{N_{o} t}=\phi(E) \sigma_{d}(E) \quad[\text { Eq. 2] }
$$

where $\sigma_{d}$ is the displacement cross section that is given by the modified Kinchin-Pease formula [3]:

$$
\sigma_{d}(E)=2 \sigma_{e}(E) / 5 T_{d} \quad[\text { Eq. 3] }
$$

where $T_{d}$ is the threshold displacement energy, which is about $40 \mathrm{eV}$ for Alloy 718 (a Nickelbased superalloy) [4]. The quantity $\sigma_{e}$ is the damage energy cross section. For neutron cross section libraries, if present, the reaction $\mathrm{mt} 444$ is $\sigma_{e}$. For other particles, and neutrons if no mt 444 is present, physics models can be used to calculate $\sigma_{e}$ using:

$$
\sigma_{e}(E)=E / N_{o} x \quad[\text { Eq. } 4]
$$

where $E$ is the mean total damage energy per source incident proton in a thin target of atom density $N$ and thickness $x$. For a material of interest the damage energy cross sections can be obtained using MCNPX either by tallying the ENDF/B-VII cross sections using an mt 444 tally multiplier or by using Eq. 4, simulating the interactions using physics models to calculate $E$ using the HTAPE3X post-processing code included in the MCNPX distribution. The DPA value is then calculated by incorporating the resulting damage energy cross sections into subsequent beam transport simulations modifying flux tallies with de and df cards.

\subsection{Thermal analysis}

Thermal as well as mechanical stress, both transient and steady state, produced by beam trips, also potentially contributes to build up of defects leading to window failure. Due to the inaccessibility of the beam window (being heavily shielded and located approximately $12 \mathrm{~m}$ below an extraction hot cell) and combined with extreme conditions present during irradiation, in situ temperature measurements are very difficult. To estimate nominal temperatures of the beam window during a typical irradiation, computational fluid dynamic (CFD) analysis was performed using ANSYS CFX. The model consists of a beam window, a target assembly, and process piping with cooling water circulating at $\sim 45 \mathrm{gpm}$ with an upward flow direction from the bottom to the top of the assembly and perpendicular to the beam direction. From CFD results, the bulk 
mean velocities are estimated through the water cooling channels and heat transfer coefficients. MCNPX heating tally was used to estimate the energy deposition in the radial direction and ANSYS finite-element analysis to estimate a thermal steady-state temperature profile for the beam window and targets.

2.7 Shear punch testing and optical images

Post Irradiation Examinations (PIEs) are often time consuming and expensive. Shear punch testing (Instron model 5567) provides an estimate of tensile properties (yield stress, ultimate stress and ductility) using a 3-mm diameter, $0.25-\mathrm{mm}$ thick disk that can be fairly easily cut from an irradiated component. The small size of specimens reduces dose and enables the possibility of multiple measurements across a component. Fracture mode can be investigated through post test observation of the backside of the specimen. The test sample is clamped in a metal fixture and a cylindrical punch is forced through a hole in the fixture causing shear along the edge of the hole (Fig. 4). The clearance between the punch and the hole is $25 \mu \mathrm{m}$ on the radius. The punch body is made of Alloy 718 and the punch itself and ball are made of tungsten carbide. The results are expressed as shear strength (MPa), which is calculated by dividing the force required to shear the sample by the area of the sheared edge. The area of the sheared edge is equal to the circumference of the punch multiplied by the thickness of the sample. All samples were tested at $\sim 25^{\circ} \mathrm{C}$ and an initial strain rate of $5 \times 10^{-4} / \mathrm{s}$. A digital optical microscope (Hirox $\mathrm{KH}-7700$ ) was used to examine shear failure surfaces and take images of the punched specimens.
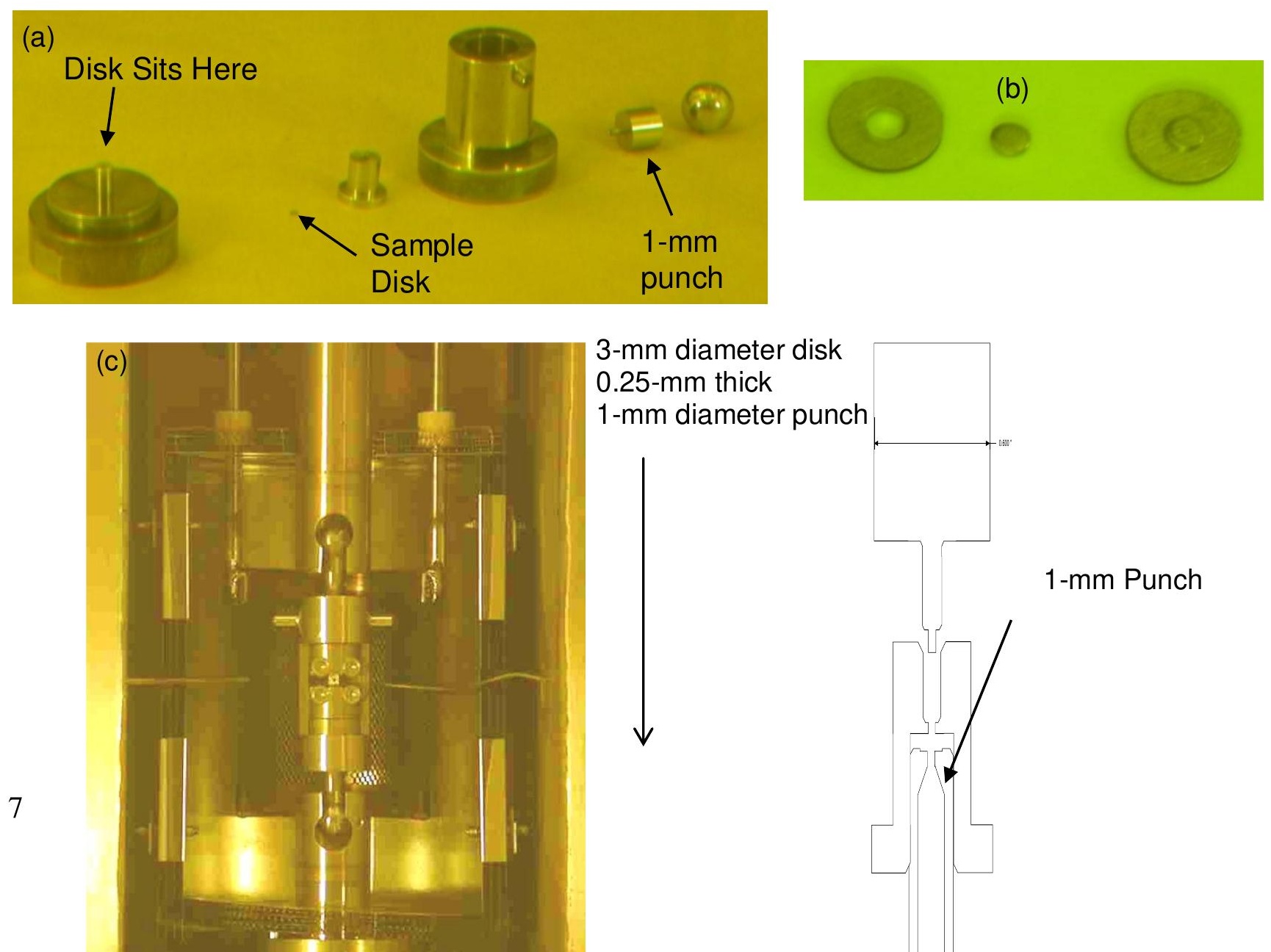
Fig. 4: A shear punch metal fixture and cylindrical punch (a); and a typical shear punch specimen (b); and shear punch testing equipment located in the CMR hot cell (c).

2.8 Focus ion beam (FIB) sample preparation and transmission electron microscopy (TEM) analysis

TEM specimens of $\sim 30 \times 10 \times 2 \mu \mathrm{m}$ were obtained from 1-mm diameter, 0.25 -mm thick punched out disks using standard FIB lift-out technique in an FEI Quanta dual beam focused FIB instrument. TEM was performed on an FEI Tecnai TF30-FEG operating at 300kV equipped with a Gatan imaging filter (GIF). EFTEM was utilized using jump ratio (2-window) technique with energy loss from K shells. Energy-filtered images were recorded by using a binning of 2 x 2 resulting in $512 \times 512$ pixel images.

\section{RESULTS}

3.1 Calculation of displacement-per-atom (dpa) and transmutation of $\mathrm{H} / \mathrm{He}$ at various locations

Typical irradiations at IPF were performed at $100 \mathrm{MeV}$ beam energy and $250 \mu \mathrm{A}$ average beam current. In addition, there were two non-typical irradiations at $40 \mathrm{MeV}, 250 \mu \mathrm{A}$ for 1.0 hour and at $100 \mathrm{MeV}, 355 \mu \mathrm{A}$ for 1.2 hours. The $40 \mathrm{MeV}, 250 \mu \mathrm{A}$ irradiation was performed 75 days prior to the $100 \mathrm{MeV}, 355 \mu \mathrm{A}$ irradiation, which is the last irradiation prior to when the beam window was changed out. Although the $40 \mathrm{MeV}, 250 \mu \mathrm{A}$ and $100 \mathrm{MeV}, 355 \mu \mathrm{A}$ beam would cause more damage than the $100 \mathrm{MeV}, 250 \mu \mathrm{A}$ the contribution to total dpa values from these two short periods are negligible due to their relatively short irradiations.

Table 1: Calculated dose (dpa), $\mathrm{H}$ and He content, and temperature at various locations in the beam window as shown in Fig. 3 at $100 \mathrm{MeV}$ beam energy.

\begin{tabular}{ccccc}
\hline Sample & dpa & $\begin{array}{c}\text { H } \\
\text { (appm) }\end{array}$ & $\begin{array}{c}\text { He } \\
\text { (appm) }\end{array}$ & $\begin{array}{c}\text { Temperature } \\
\text { (C) at 250 } \boldsymbol{\mu A} \\
\text { beam current }\end{array}$ \\
\hline $\mathbf{1 - 2}$ & 8.6 & 7784 & 1239 & 100 \\
$\mathbf{3 - 9}$ & 11.3 & 10406 & 1634 & 120 \\
\hline
\end{tabular}




\begin{tabular}{|c|c|c|c|c|}
\hline $10-11$ & 2.0 & 1832 & 289 & 68 \\
\hline $12-13$ & 2.8 & 2658 & 391 & 60 \\
\hline 14 & 3.3 & 2958 & 408 & 60 \\
\hline $\begin{array}{c}15- \\
16\end{array}$ & 3.6 & 3323 & 531 & 39 \\
\hline $17-18$ & 0.2 & $131-115$ & $19-24$ & 34 \\
\hline 19 & 0.7 & 546 & 81 & 34 \\
\hline $20-21$ & 0.8 & 747 & $128-87$ & 34 \\
\hline 22 & 1.4 & 1276 & 183 & 34 \\
\hline$A-B$ & 9.3 & 8633 & $1261-1380$ & 105 \\
\hline C-E & 10.6 & 9690 & 1556 & 115 \\
\hline F-K & 9.0 & 8305 & 1341 & 103 \\
\hline $\mathbf{L}$ & 2.2 & 1844 & 232 & 60 \\
\hline M & 2.3 & 2191 & 338 & 60 \\
\hline $\mathbf{N}$ & 2.5 & 2261 & 389 & 60 \\
\hline O-P & 3.5 & 3250 & 545 & 60 \\
\hline Q-S & 0.2 & $125-273$ & $24-34$ & 34 \\
\hline $\mathbf{T}$ & 0.5 & 405 & 71 & 34 \\
\hline U & 1.0 & 991 & 128 & 34 \\
\hline V & 1.2 & 1225 & 157 & 34 \\
\hline
\end{tabular}

${ }^{*}$ Hydrogen and helium concentration in atomic parts per million $\left(10^{-6}\right.$ atom fraction $)$ with respect to the total numbers of atoms in the alloy 718 disk $\left(4.0 \times 10^{20}\right)$.

Table 1 shows MCNPX tally results of average dpa, $\mathrm{H}$ and He content from both proton and neutron fluences and ANSYS temperature results for each of the 3-mm O.D. and 0.684-nmm thick disks. Samples with similar dpa values are grouped. From the integrated beam charge data ( 0.394 mA-y), the average dpa, $\mathrm{H}$ and He content was estimated for each sample location. As expected, samples \#3-9 at the peak intensity of the beam (highest radiation dose area) show the highest dpa, $\mathrm{H}$ and $\mathrm{He}$ content, and temperature of $\sim 11.3,10,400 \mathrm{appm}, 1,600 \mathrm{appm}$, and $122^{\circ} \mathrm{C}$, respectively. These values decrease for the samples outside the beam collimator area and towards the edge of the beam window. Taking into account the long irradiation period with the variation in beam parameters, the results of code calculations of the total fluence, damage production and 
transmutation rates are a reasonable estimate. The hydrogen and helium transmutation rates are on the order of $\sim 900 \mathrm{appm} / \mathrm{dpa}$ and $\sim 140 \mathrm{appm} / \mathrm{dpa}$, respectively.

\subsection{Cooling water velocity and temperature distribution}

CFD results indicate that water flows through each cooling channel from the bottom to the top of the assembly at an average velocity of $\sim 2.45 \mathrm{~m} / \mathrm{s}$ (Fig. 5a). ANSYS thermal analysis results show a temperature profile of the beam window at $100 \mathrm{MeV}, 250 \mu \mathrm{A}$ using an average heat transfer coefficient (Fig. 5b). The maximum temperature of the beam window occurs at the peak density of the rasterred beam and is at $\sim 122^{\circ} \mathrm{C}$. The lowest temperature $\left(\sim 34^{\circ} \mathrm{C}\right)$ is expected at around the edge of the beam window. From the MCNPX and ANSYS thermal modeling, the samples at the peak beam density yield highest beam energy deposition and temperature values.
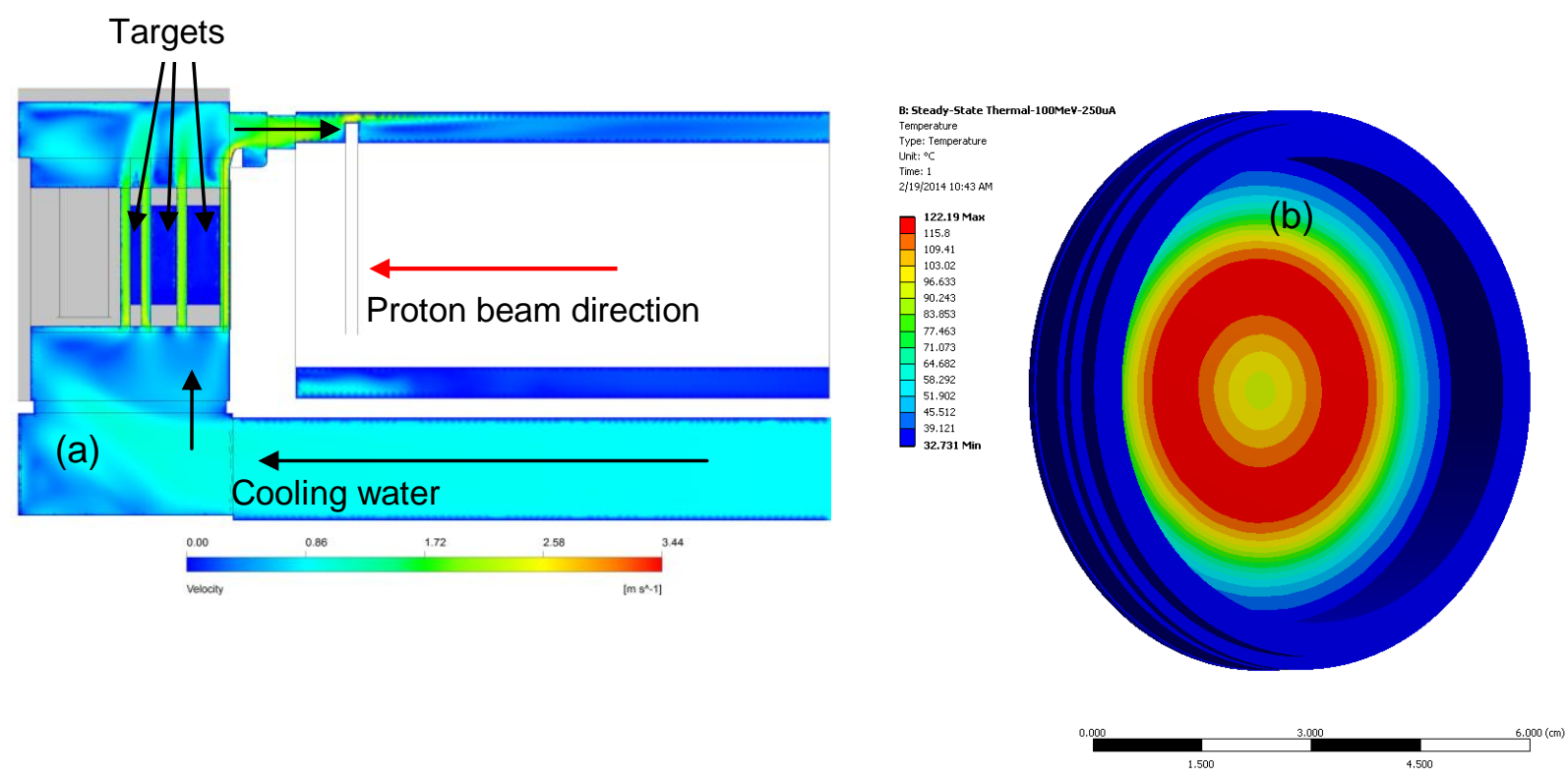

Fig. 5: Velocity distribution of cooling water in the system with volume flow rate of $45 \mathrm{gpm}$ (a) and temperature profile in degree Celcius of the beam window at $100 \mathrm{MeV}, 250 \mu \mathrm{A}$ beam current (b).

At $100 \mathrm{MeV}, 355 \mu \mathrm{A}$ and $40 \mathrm{MeV}, 250 \mu \mathrm{A}$, we would expect the beam window thickness of $0.684 \mathrm{~mm}$ to absorb higher energy and the peak temperatures are $164^{\circ} \mathrm{C}$ and $222^{\circ} \mathrm{C}$, respectively. The lowest temperatures for these two short irradiations are $37^{\circ} \mathrm{C}$ and $47^{\circ} \mathrm{C}$, respectively. Because the largest increase in temperature occurred at the end of the irradiation 
period and prior to the window was being replaced, $\sim 100^{\circ} \mathrm{C}$ higher than the typical irradiation temperature, this may have had an effect on the final microstructure especially in the highest dose locations. The effect of higher temperatures on the microstructure and mechanical properties is discussed in section 4.

\subsection{Shear and tensile properties}

Shear testing was performed on all 6 unirradiated samples and 22 out of 25 irradiated samples. Load/displacement is measured from a load cell on the test frame and the crosshead displacement to obtain typical load-displacement curves as shown in Figures 5a, and 6-7. The deviation point from the initial linear slope and the maximum point of the graph are related to the shear yield and ultimate shear strength, respectively. The shear yield and ultimate shear strengths of the 3 unirradiated samples 4-6 are 230-250 MPa and $700 \mathrm{MPa}$, respectively (Fig. 6a). Three unirradiated dog bone shaped samples were prepared for uniaxial testing. The tensile and ultimate tensile strengths are $435 \mathrm{MPa}$ and $900 \mathrm{MPa}$, respectively (Fig. 6b).
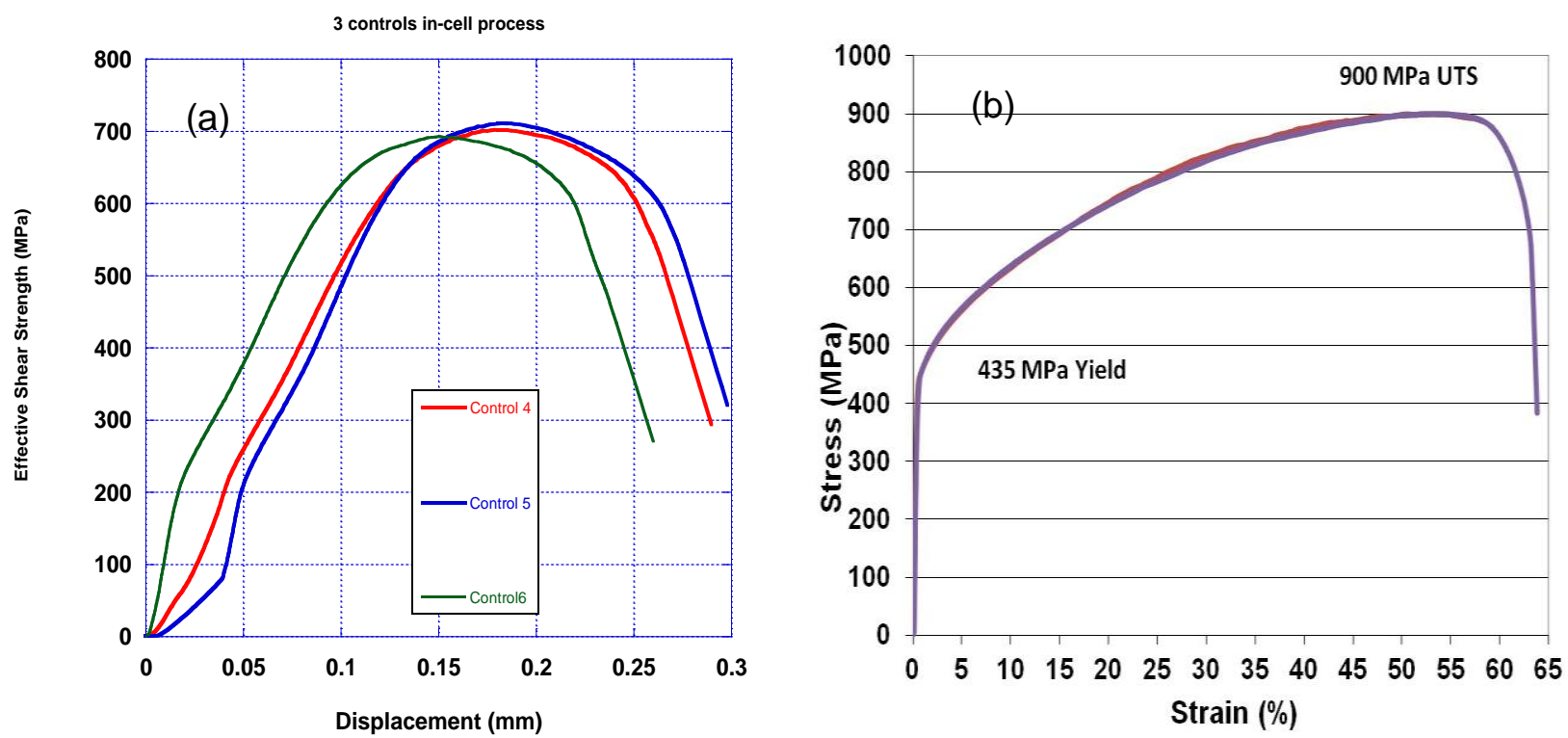

Fig. 6: Shear (a) and tensile (b) stress-strain curves of unirradiated Alloy 718 samples.

A number of correlations have been developed between features of the load-displacement curve and mechanical properties such as yield strength, ultimate tensile strength, and ductility [5]. If $1 \%$ offset in shear yield value is assumed to accommodate for materials-to-materials variation in the shear punch test machine compliance, the correlations between the tensile and shear yield and ultimate yield strengths are 1.77 and 1.28, respectively. They are in good agreement with literature values of 1.73 and 1.40 , respectively [6].

Figure 7 shows shear stress-strain curves of samples at various locations in the high irradiation dose area (samples \#3-6 and \#8-9, dose = 11.3 dpa). Measurements of shear yield 
and ultimate shear strength are consistent at various locations and are approximately $450 \mathrm{MPa}$ and $750 \mathrm{MPa}$, respectively.

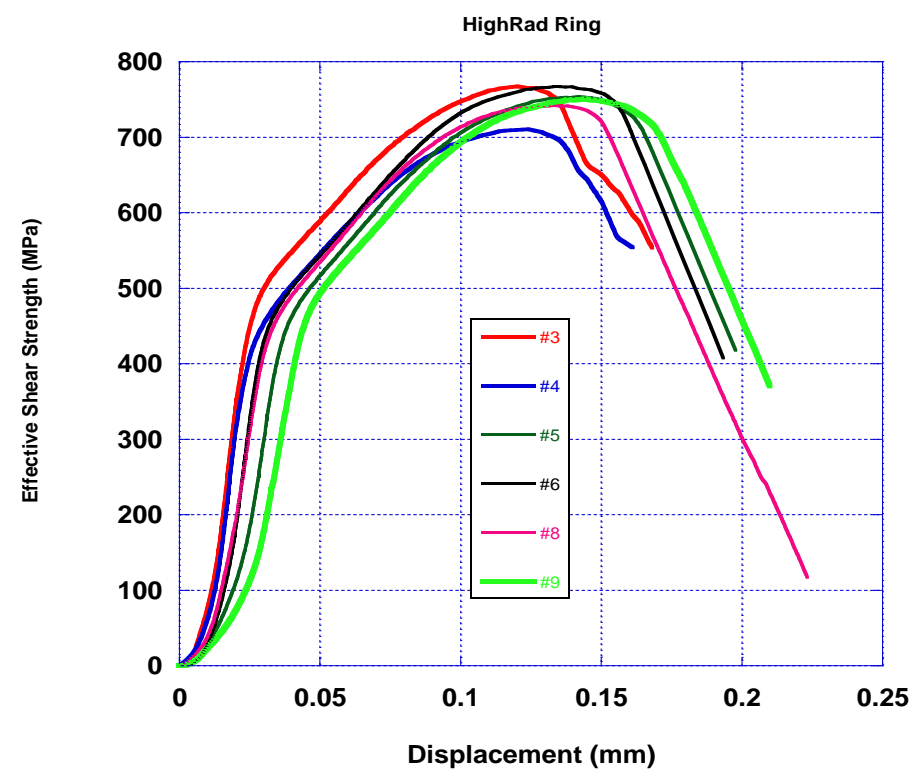

Fig. 7: Shear stress-strain curves of samples at various locations in the high irradiation dose area (11.3 dpa).

In Fig. 8, the stress-strain curves are shown for one unirradiated and 8 irradiated samples at various locations. The unirradiated sample exhibits the lowest of shear yield and ultimate shear stress values. Both shear yield and shear maximum stresses increases with increasing irradiation dose indicating a sign of irradiation hardening. The highest dose samples \#3-4 show the smallest increase in yield and ultimate shear stress and are approximately $500 \mathrm{MPa}$ and 750 $\mathrm{MPa}$, respectively. Contrary to expectation, samples outside the beam collimator and towards the edge of the window (samples \#10-11 and \#17-18), where irradiation dose was calculated to be relatively low (2.0 dpa and 0.2 dpa respectively), have the highest shear yield ( $650 \mathrm{MPa})$ and ultimate shear ( 900 MPa) stresses in comparison with the other samples. These results are consistent with microstructural observations and explained later in this paper. 


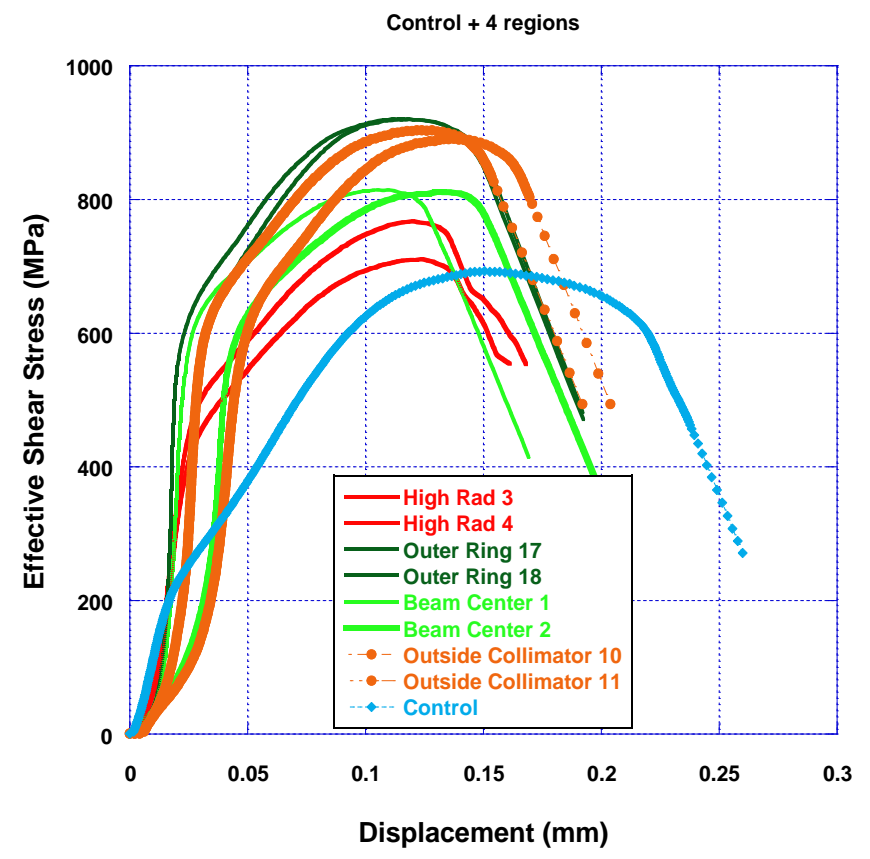

Fig. 8: Shear stress-strain curves of samples at various irradiated areas and control sample \#1 from unirradiated Alloy 718.

3.4 Optical images and the beam window ductility

The fracture surfaces of all shear punch specimens were examined with a digital optical microscope at 60-160X magnification. For comparison, figures 9-11 show typical images of the fracture surface and back side of shear punch specimens of unirradiated samples \#1 and \#6, low irradiation dose samples \#17 and \#20 (dose = 0.2-0.7 dpa) and high irradiation dose sample \#3 $($ dose $=11.3 \mathrm{dpa})$. The exit sides show no brittle fracture characteristic (such as fracture along the grain boundaries), which indicates there is no significant change in ductility. 


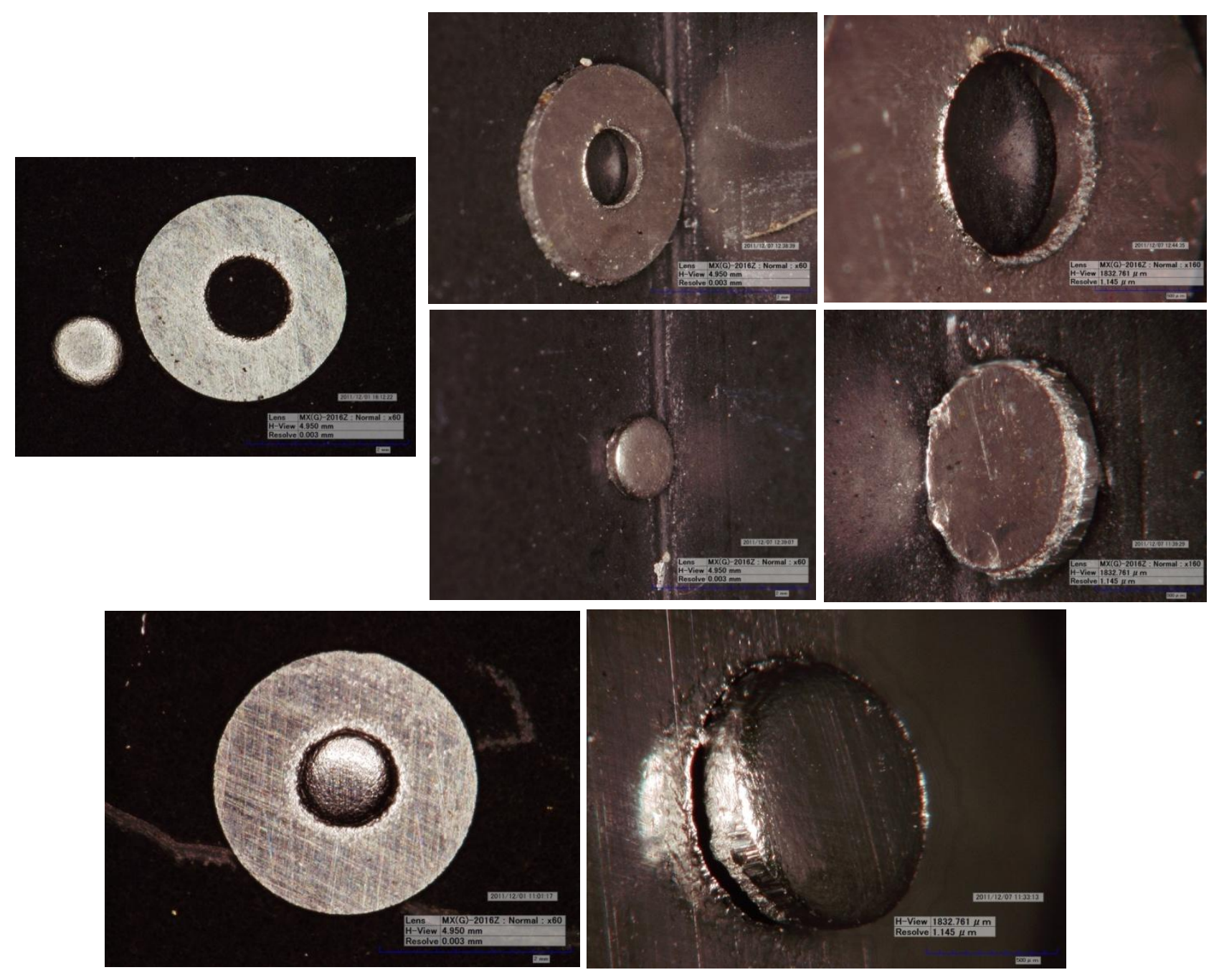


Fig. 9: Optical images of unirradiated samples \#1 (top) and \#6 (bottom).
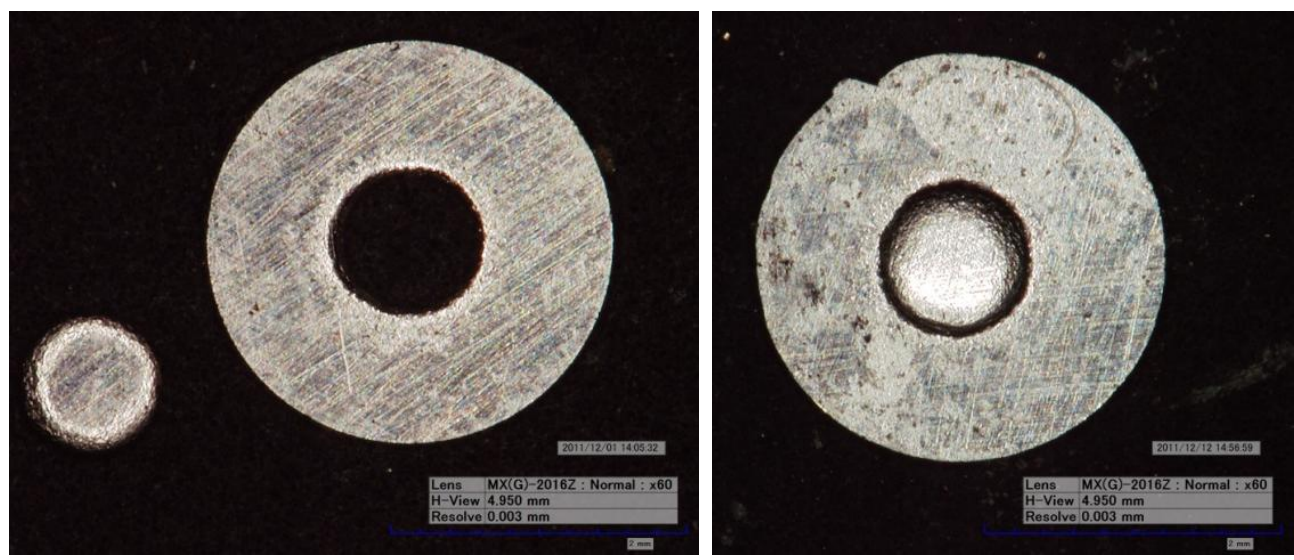

Fig. 10: Optical images of the low irradiation dose (0.2-0.7 dpa) samples \#17 (left) and \#20 (right).
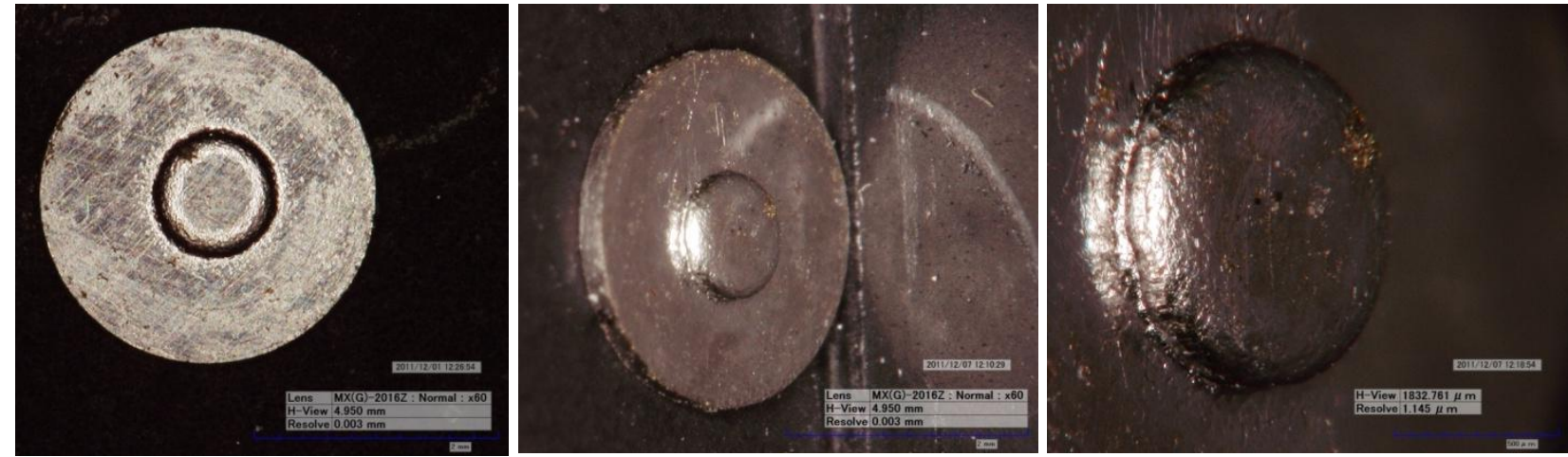

Fig. 11: Optical images of the high irradiation dose sample \#3 (dose = $11.3 \mathrm{dpa})$.

\subsection{Microstructural characterization}

In order to gain an understanding of the microstructural changes due to irradiation (dpa and temperature) one unirradiated and 4 irradiated samples (\#5, E, 16 and 19; dose $=11.3 \mathrm{dpa}$, $10.6 \mathrm{dpa}, 3.6 \mathrm{dpa}$ and $0.7 \mathrm{dpa}$ respectively) were selected for TEM analysis. Figure 12a shows a bright field TEM image of an unirradiated sample with some dislocations. In some areas, isolated larger precipitates of $\delta$ phase particles and carbides were seen as well. Figure $12 \mathrm{~b}$ shows a selected area diffraction pattern from $\mathrm{z}=[111]$ zone axis. There is no evidence of superlattice reflections originating from $\gamma^{\prime}$ or $\gamma^{\prime \prime}$ precipitates indicating the unirradiated alloy was solutionannealed (SA) but not precipitation-hardened (PH). 

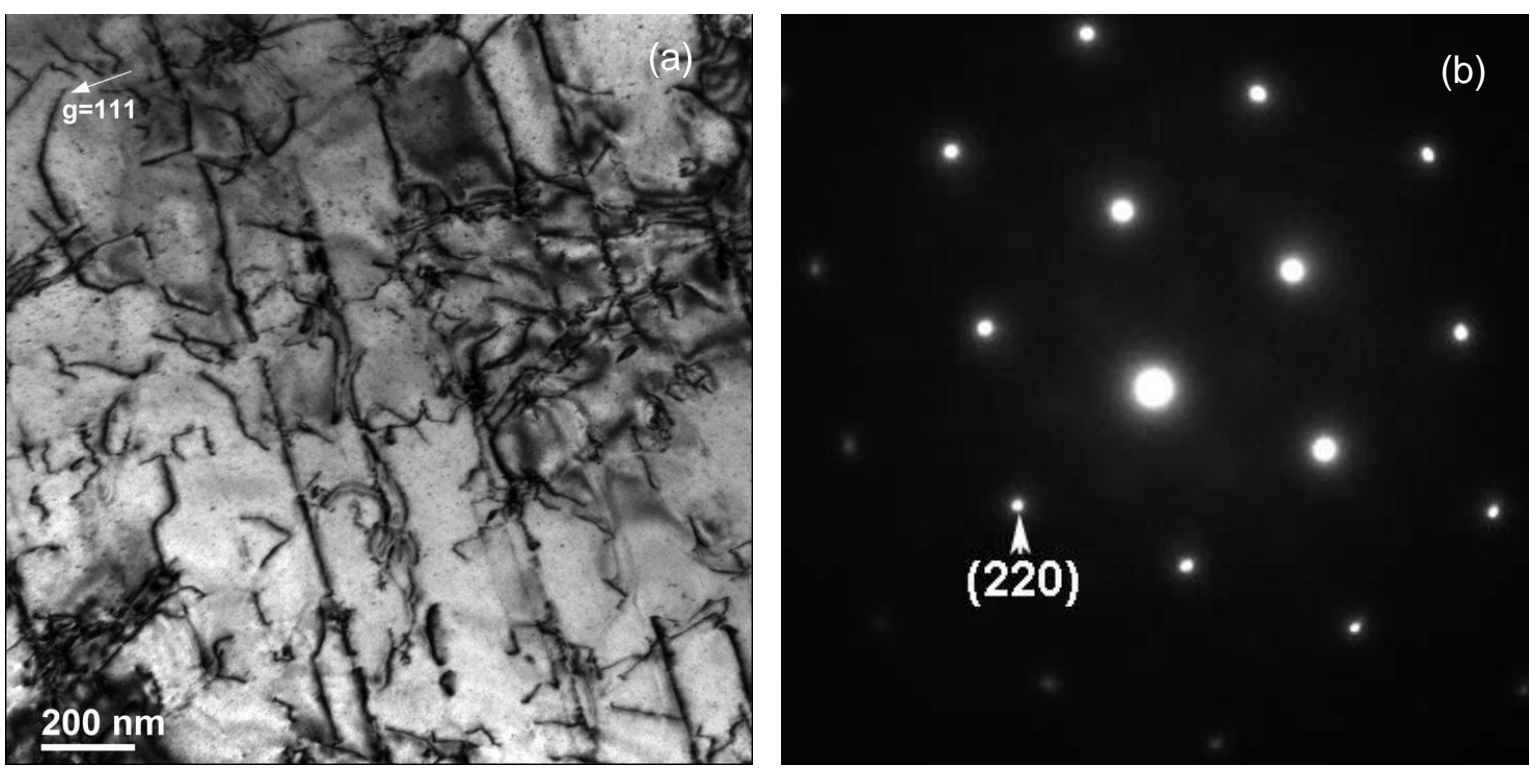

Fig. 12: Bright field TEM image showing dislocations (a); selected area diffraction pattern from $\mathrm{Z}=[111]$ does not indicate presence of $\gamma^{\prime}$ or $\gamma^{\prime \prime}$ precipitates in unirradiated sample (b).

In Fig. 13, bright field TEM images are shown together with the SAD pattern from $\mathrm{z}=$ [001] of the irradiated sample \#5, which is in the highest dose region, has an estimated $11.3 \mathrm{dpa}$. As expected, this highest radiation dose sample qualitatively has a high dislocation density in comparison to the unirradiated sample. Average loop size is calculated to be $\sim 37 \mathrm{~nm}$ with a density of $\sim 1.3 \times 10^{21} \mathrm{~m}^{-3}$. Note that SAD does not show superlattice reflections indicating absence of any second phase precipitate. However, some larger precipitates were found similar to unirradiated sample. Several through-focal images did not indicate presence of cavity/bubble formation.
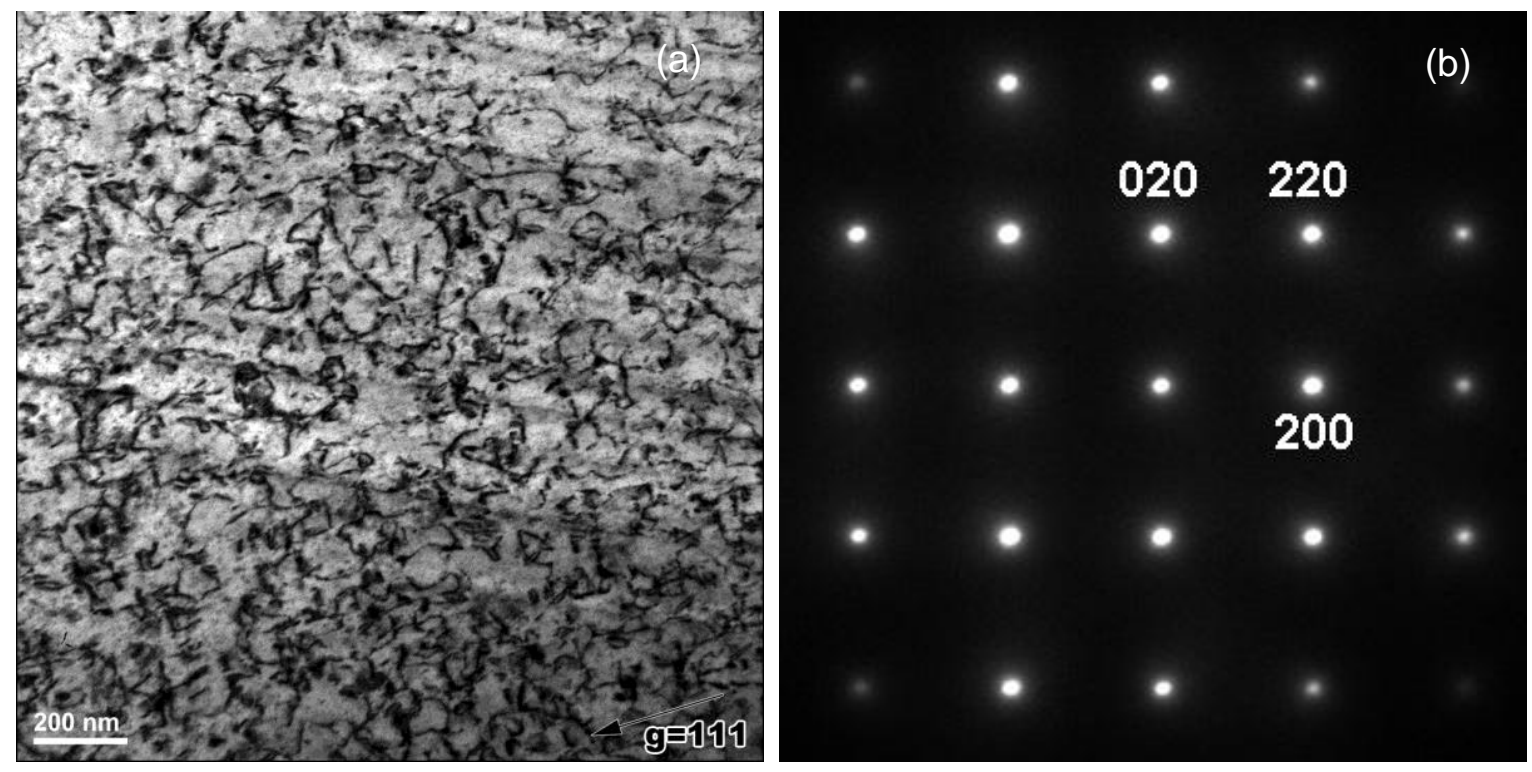
Fig.13: Bright field TEM image shows small loops and dislocations (a); and SAD from z= [001] does not indicate presence of $\gamma^{\prime}$ or $\gamma^{\prime \prime}$ precipitates in sample \#5 (11.3 dpa) (b).

Bright field TEM image of dislocation loops is seen in Fig. 14 (a). This sample (\#19), which is in the lowest radiation dose region, has an estimated dose of 0.7 dpa and higher dislocation density $\left(1.9 \times 10^{21} \mathrm{~m}^{-3}\right)$ but smaller loop size $(\sim 11 \mathrm{~nm})$ compared to the previous sample. In addition, under focus $(\sim 1 \mu \mathrm{m})$ TEM image in (b) shows a high density of bubbles/voids that are on the order of $\sim 2 \mathrm{~nm}$. Furthermore, SAD pattern in (c) shows superlattice reflections due to presence of $\gamma^{\prime \prime}$ precipitates. $\mathrm{Ni}, \mathrm{Ti}$, and $\mathrm{Al}$ enriched precipitates are clearly seen in jump ratio images in (d) around the same region as the (b). 

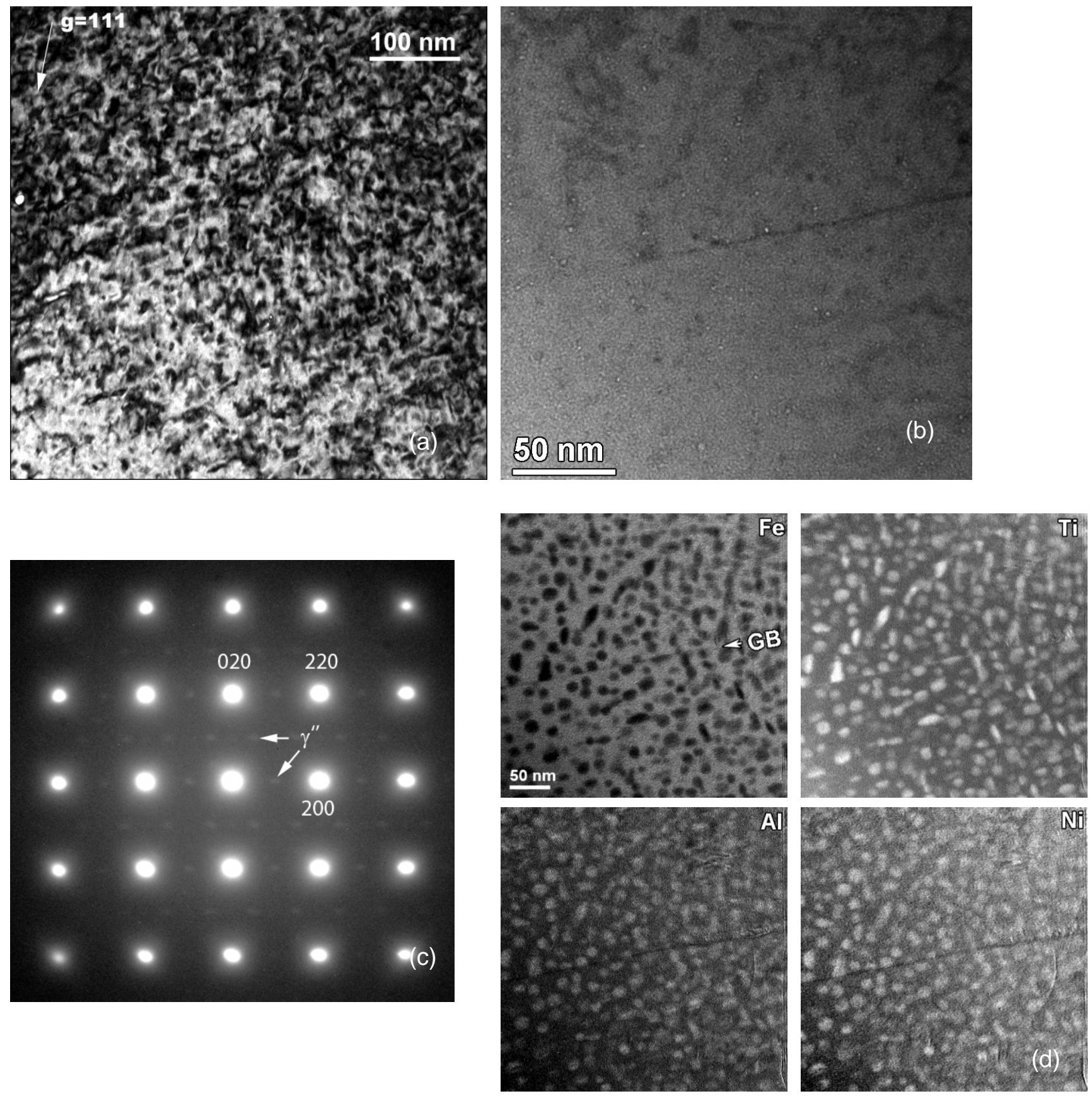

Fig. 14: Bright field TEM image shows a high density of dislocation loops(a); Underfocus TEM image shows bubbles(b); SAD shows presence of $\gamma^{\prime \prime}$ precipitates(c); and EFTEM jump ratio images of $\mathrm{Fe}, \mathrm{Ni}, \mathrm{Al}$, and Ti showing the precipitates in low dose sample \#19 (0.7 dpa) (d).

\section{DISCUSSION}

Notable changes in both microstructure and mechanical properties were observed in SA Alloy 718 after irradiation. The microstructure of the SA irradiated Alloy 718 is dominated by black dot damage and loops. The average loop size increases with dose. The average loop size is 
similar to reported values in the literature by Sencer et al. for PH Alloy 718 at similar temperature and doses [7]. On the other hand, to the best of our knowledge formation of $\gamma^{\prime \prime}$ in SA Alloy 718 under irradiation is not reported in the literature previously. Solution annealed Alloy 718 is a single phase alloy. In order to observe the formation of $\gamma^{\prime \prime}$ precipitates in the irradiated samples at low temperatures $\left(37^{\circ} \mathrm{C}\right)$, it must be enhanced due to irradiation since it normally requires thermal aging at elevated temperatures $\left(750^{\circ} \mathrm{C}\right)$ to form these precipitates $[8,9]$. However, previous results show that they are not stable under irradiation at low temperatures. Disordering starts at $0.1 \mathrm{dpa}$ and complete disordering occurs by $0.6 \mathrm{dpa}[7,10]$. This manifests itself as the decrease in yield strength in irradiated PH Alloy 718 [11]. We suspect that formation of the precipitates along the edge ( $\sim 0.2-0.7 \mathrm{dpa})$ could be due to a lower flux rate in this region compared to an order of magnitude higher flux rate in the center ( 11.3 dpa). It is possible that in the high dose central region precipitates initially formed at low dose and disordered after further irradiation or perhaps the precipitates did not form at all because of the higher dose rate. It is also interesting to note that only $\gamma^{\prime \prime}$ superlattice reflections are seen but not $\gamma^{\prime}$. Under thermal aging, formation of $\gamma^{\prime}$ precedes the formation of $\gamma^{\prime \prime}$. In fact $\gamma^{\prime}$ facilitates nucleation site for $\gamma^{\prime \prime}$. In the absence of $\gamma^{\prime}$ the formation mechanism of $\gamma^{\prime \prime}$ may change as well. A systematic study to investigate the formation of precipitates under irradiation will be focus of a future study. In addition, the significant amount of trapped $\mathrm{He} / \mathrm{H}$ in the lowest irradiation dose region and no trapped helium/hydrogen in the highest irradiation dose region from the TEM data are not consistent with MCNPX calculations. One possible explanation is that these bubbles are filled with hydrogen. At the high temperature in the high dose region $\left(\sim 222^{\circ} \mathrm{C}\right)$ that was calculated to occur at the end of the irradiation period hydrogen diffused out whereas in the low temperature region at the edge the bubbles of hydrogen retained. Further studies include the determination of whether the bubbles are filled with $\mathrm{He}$ or $\mathrm{H}$ and their content at different locations.

Higher hardening was observed around the edge of window with the lower irradiation dose $(0.7 \mathrm{dpa})$. This is not surprising based on the high density of $\gamma^{\prime \prime}$ precipitates and defect clusters observed in the microstructural investigation. These $\gamma^{\prime \prime}$ precipitates are the primary contribution to the strength of Ni-based alloys due to coherency strains arising from lattice distortion as these precipitates form $[8,9,12,13]$. The observed highest radiation-induced hardening is attributed to the formation of these $\gamma^{\prime \prime}$ precipitates together with a high density of defect clusters and bubbles/voids shown in Fig. 14. Byun et al. reported similar increase in yield strength in SA Alloy 718 after 1.2 dpa neutron irradiation in HFIR [14]. However, they did not report microstructure. In contrast to low dose irradiated sample in our study, the radiation induced hardening decreases in the highest irradiation dose region (11.3 dpa). A high density of irradiation induced defect clusters is also present in this region. However, microstructural investigations did not indicate presence of $\gamma^{\prime \prime}$ precipitates or bubbles/cavities. Therefore these will not contribute to hardening. In addition, the temperature increase in irradiation at the end of the irradiation period, may also have affected the dislocation microstructure resulting in some 
annealing. As a result less irradiation induced hardening is consistent with the microstructure observation in the highest dpa region.

James et. al. reported a slight increase in strength (hardening) and a drastic reduction in elongation as a function of dose of the $\mathrm{PH}$ Alloy 718 beam window irradiated up 20 dpa at $\sim 400^{\circ} \mathrm{C}$ at the LANSCE Lujan Neutron Scattering Center. Specifically, the 20 dpa test failed with zero elongation [15]. Maloy et. al. showed excellent ductility up to $18 \mathrm{dpa}$ at $\sim 400^{\circ} \mathrm{C}$ on spallation irradiated SA Alloy 718 [16]. From the data showing retention of ductility for all conditions tested on this window, we have raised the irradiation limit on the future window to 18 dpa. Future testing will involve analysis of beam windows up to 18 dpa to see if the lifetime can be extended further.

\section{CONCLUSIONS}

Mechanical properties and microstructure of a solution annealed Alloy 718 beam window have been investigated after irradiation to a total dose of $11.3 \mathrm{dpa}$ at a maximum irradiation temperatures of $122^{\circ} \mathrm{C}$ (with short excursions to 163 and $222^{\circ} \mathrm{C}$ ). Dose was determined from performing autoradiography on the window coupled with calculations based on the irradiation history while irradiation temperature was determined from detailed thermal hydraulic calculations. The mechanical properties were investigated through cutting 3-mm disks from specific locations in the window and performing shear punch testing at room temperature. The microstructure was characterized from shear punched out disks with TEM. The following conclusions can be drawn from this in depth investigation:

1. From the investigation of failure on the exit side of the shear punch specimens and the significant work hardening capacity evident by a large difference between the shear yield and shear ultimate stress, significant ductility remains in this window after irradiation.

2. At the lower dose of $\sim 0.7 \mathrm{dpa}$, the higher hardening was observed. This hardening was attributed to formation $\gamma^{\prime \prime}$ precipitates, a high density of irradiation induced defect clusters and cavities/bubbles.

3. At the highest dose of $\sim 11.3 \mathrm{dpa}$, significant hardening was observed but much less than observed in the $0.7 \mathrm{dpa}$ region. No second phase precipitates or voids/bubbles were observed.

Future work on the current and future beam window includes microstructure analysis of samples in the center of the window ( $\sim 9 \mathrm{dpa})$ where the shear yield was slightly higher than that of samples in the center of the beam (11.3 dpa), elemental content analysis of the gas bubbles, and implementation of in-situ temperature measurement. 


\section{ACKNOWLEDGEMENTS}

This material is based upon work supported by the U.S. Department of Energy, Office of Science, via funding from the Isotope Development and Production for Research and Applications subprogram in the Office of Nuclear Physics and the Los Alamos National Laboratory (LANL) / Laboratory Directed Research \& Development (LDRD) Program.

We wish to thank many members in the Los Alamos National Laboratory AOT-MDE, AOT-OPS, Mr. Frank Valdez, and RP for their contributions in the beam window replacement and radiation protection. We acknowledge the efforts of the C-IIAC CMR hot cell team in the beam window disassembly, testing, and disposal. We also acknowledge effort of OS-PT group in transporting the beam window from LANSCE to CMR facility. Finally, we would like to thank Dr. Meiring Nortier for his helpful discussions. 


\section{REFERENCES}

[1] D. B. Pelowitz, ed. “MCNPX ${ }^{\mathrm{TM}}$ User's Manual," Los Alamos National Laboratory report LA-CP-07-1473 (April 2008).

[2] Fundamentals of Radiation Material Science, Gary S. Was, Springer-Verlag Berlin Heidelberg 2007.

[3] G. H. Kinchin and R. S. Pease, Rep. Prog. Phys. 18 (1955).

[4] H. H. Andersen, Appl. Phys. 18, (1979) 131.

[5] Lucas G. E. et. al., J. of Nuc. Mat., vol 122, Issues 1-3, (1984) 429-434.

[6] Toloczko et. al., J. of Nuc. Mat., vol 307-311, Issue 2, (2002) 1619-1623.

[7] B. H. Sencer, G. M. Bond, F. A. Garner, M. L. Hamilton, B. M. Oliver, L. E. Thomas, S. A. Maloy, W. F. Sommer, M. R. James, and P. D. Ferguson, J. of Nuc. Mat. 283, (2000) 324-328.

[8] S. J. Hong, W. P. Chen, and T. W. Wang, Metallurgical and Materials Transactions A, vol 32A, (2001) 1887-1901.

[9] H. E. Jianhong, J. Mater. Sci. Technol., vol 10, (1994) 293-303.

[10] N. Hashimoto, J. D. Hunn, T. S. Byun, L. K. Mansur, J. of Nuc. Mat. 318, (2003) 300-306.

[11] S. A. Maloy, M. R. James, G. Willcutt, W.F Sommer Jr., M. Sokolov, L.L. Snead, M.L. Hamilton, F. Garner, J. of Nuc. Mat., 296 (2001) 119-128.

[12] J. M. Oblak, D.F. Paulonis, S. Duvall, Metall. Trans. 5 (1974) 143-153.

[13] M. Sundararaman, P. Mukhopadhyay, S. Baerjee, Acta Metall. 36 (1988) 847-864.

[14] T. S. Byun, K. Farrell, J. of Nuc. Mat., 318, (2003) 292-299.

[15] M. R. James, S. A. Maloy, F. D. Gac, W. F. Sommer, J. Chen, H. Ulmaier, J. of Nuc. Mat. 296, (2001) 139-144.

[16] S. A. Maloy, T. J. Romero, P. Hosemann, M. B. Toloczko, Y. Dai, J. of Nuc. Mat. 417, (2011) 1005-1008. 